\title{
Salivary Glucosyltransferase B as a Possible Marker for Caries Activity
}

\author{
A.M. Vacca Smith ${ }^{a} \quad$ K.M. Scott-Anne ${ }^{b}$ M.T. Whelehan ${ }^{c}$ R.J. Berkowitz ${ }^{c}$ \\ C. Feng ${ }^{d}$ W.H. Bowen ${ }^{b}$ \\ ${ }^{a}$ Department of Microbiology and Immunology, ${ }^{b}$ Center for Oral Biology, ${ }^{\mathrm{C}}$ Eastman Department of Dentistry and \\ ${ }^{\mathrm{d}}$ Department of Biostatistics and Computational Biology, University of Rochester, Rochester, N.Y., USA
}

\section{Key Words}

Dental caries · Glucosyltransferase B · Saliva · Streptococcus mutans

\begin{abstract}
Bacteria-derived glucosyltransferases (Gtf) (EC 2.4.1.5), through synthesizing glucan polymers from sucrose and starch hydrolysates, play an essential role in the etiology and pathogenesis of caries. We attempted to correlate the levels of Gtf in whole saliva with the prevalence of carious lesions in young children. We examined saliva from children who were either free of overt carious lesions, or had severe early childhood caries (mean dmfs = $18.72 \pm 9.0 \mathrm{SD}$ ), for Gtf by direct enzyme assay. The levels of GtfB, GtfC and GtfD from Streptococcus mutans in the saliva using monoclonal/specific antibodies in an enzyme-linked immunosorbent assay were determined. Multiple logistic regression analyses with model selection showed that GtfB levels correlated with $d m f s$ values of the subjects $(p=0.006)$. There was no correlation between total Gtf activity as measured by direct enzyme assay and dmfs values. There was a strong correlation between mutans streptococci populations in saliva and caries activity. Collectively, these data show that GtfB levels in saliva correlate strongly with presence of clinical caries and with number of carious lesions in young children. It is also possible to measure different Gtfs, separately, in whole sali-
\end{abstract}

va. These observations may have important clinical implications, may lead to development of a chair side caries activity test and support the importance of GtfB in the pathogenesis of dental caries.

Copyright $\odot 2007$ S. Karger AG, Basel

Early childhood caries (ECC) involves tooth decay of primary teeth in young children [Tinanoff, 1998] and is a public health problem of global proportions [Milnes, 1996]. A simple reliable test to determine caries activity before the appearance of carious lesions is unavailable. Glucosyltransferases (Gtf) (EC 2.4.1.5) have been shown to be essential for the expression of virulence of Streptococcus mutans in rodent models [Yamashita et al., 1993]. Gtf enzymes synthesize glucans in situ on tooth and bacterial surfaces which serve as binding sites for streptococci and other organisms [Schilling et al., 1989; Schilling and Bowen, 1992]. S. mutans synthesizes at least $3 \mathrm{gtf}$ gene products. GtfB polymerizes an insoluble glucan composed predominantly of $\alpha 1,3$-linked glucose moieties. GtfD produces a soluble glucan, which has predominantly $\alpha 1,6$-linked glucosyl units, and GtfC synthesizes a polymer with a mixture of $\alpha 1,3$-linked glucose moieties and $\alpha 1,6$-linked glucose [Loesche, 1986; Hanada and Kuramitsu, 1988, 1989]. There may be numerous sources of Gtf in saliva, and salivary Gtf could be derived from

\section{KARGER}

Fax +41613061234 E-Mail karger@karger.ch www.karger.com (c) 2007 S. Karger AG, Basel

0008-6568/07/0416-0445\$23.50/0

Accessible online at:

www.karger.com/cre
William H. Bowen, BDS, PhD

University of Rochester, Center for Oral Biology

601 Elmwood Avenue, Box 611

Rochester, NY 14642 (USA)

Tel. +1 585275 0772, Fax +1 585276 0190, E-Mail William_Bowen@urmc.rochester.edu 
S. mutans, S. sobrinus and S. sanguinus [Hamada and Slade, 1980; Vacca Smith and Bowen, 2000].

Clearly Gtfs play a critical role in the pathogenesis of caries and furthermore, the enzymes are present in whole saliva. We therefore hypothesized that the amount of Gtfs collectively or separately could be correlated with caries activity. Should such a correlation be shown, the way would be open to determine whether evaluation of Gtfs could have predictive value.

\section{Materials and Methods}

\section{Antibodies}

Polyclonal antisera to Gtfs $\mathrm{C}$ and $\mathrm{D}$ were raised in rabbits to purified GtfC or GtfD [Venkitaraman et al., 1995; Wunder and Bowen, 2000] and were made monospecific for their target Gtfs by exposing these antisera to hydroxyapatite beads coated with purified nontarget Gtfs, thereby removing antibodies cross-reactive to nontarget Gtf enzyme (unpublished data). Monospecificity of antibodies in the antisera was determined by ELISA assay (see method below) using purified GtfB, GtfC and GtfD as target antigens. ELISA and Western blot assays were also performed to verify that the antibodies did not cross-react with salivary constituents.

Monoclonal antibody to GtfB was prepared by fusion of spleen cells from mice immunized with purified GtfB [Venkitaraman et al., 1995] with myeloma cell line (ATCCTIB-9) and cloning by limiting dilution using the techniques described by Ivanyi and Davies [1980]. The specificity of monoclonals in hybridoma cell line culture supernatant fluids was determined by ELISA assay (see method below) using purified GtfB, GtfC and GtfD as target antigens, and the antibody was found specific for GtfB.

All animal manipulations were performed in accordance with guidelines established by the University of Rochester Committee on Animal Research.

\section{Dental Examination and Saliva Collection}

Whole saliva was collected from 50 children, 25 of whom were diagnosed as having ECC and 25 were clinically caries-free, at the time of their dental examination. All of the ECC subjects were recipients of New York State Medicaid, indicating that they were from families of low economic status. The caries-free subjects had private insurance, showing that they were middle-income families. We chose to carry out our study in children with ECC because we wanted to ensure that our subjects were indeed caries-active. Human subject recruitment, consent and saliva collection were performed in accordance with a protocol approved by the University of Rochester Institutional Review Board. Every subject was given a unique identifier and information about the subjects was kept confidential in accordance with HIPPA regulations. Study subjects were recruited from the patient population of the Division of Pediatric Dentistry, Eastman Dental Center, and University of Rochester. The criteria for establishing a diagnosis of severe ECC were carious lesions affecting at least 2 of the 4 maxillary primary incisors and 2 of the 4 buccal segments.

Caries status was evaluated by 2 trained and calibrated clinical examiners (M.T.W. and R.J.B.) at the time of entry of the subjects into the study. The examinations were done with the aid of a dental mirror and explorer after the teeth had been dried with compressed air. The ECC subjects had their dental exam performed in hospital operating rooms after general anesthesia had been induced. The caries-free subjects had their examination performed during a visit to the pediatric outpatient clinic while they sat in a dental chair. The examiners were recalibrated every 3 months during the study period. No opportunity was provided for performing repeated evaluations on the same study subject by the same examiner and thus no quantitative assessment of intraexaminer reliability was calculated. A surface was declared as having carious lesions per the criteria of Radike [1972]. White spot lesions were included in the caries scoring, they were not penetrated with an explorer.

An unstimulated whole saliva sample was obtained from each subject. The sample was obtained through a disposable saliva ejector attached to a $15-\mathrm{ml}$ sterile centrifuge tube, which in turn was attached to a vacuum pump [Leverett et al., 1993a]. Approximately $2 \mathrm{ml}$ of saliva was collected from each subject. Group A subjects had their saliva sample taken before their oral rehabilitation under general anesthesia and accordingly had nothing to eat or drink for at least $8 \mathrm{~h}$ prior to collection. The parents of group $B$ subjects were instructed to give their children no food or beverage for $2 \mathrm{~h}$ prior to saliva collection.

After collection, the saliva was immediately transported on ice to the laboratory and assayed within $1 \mathrm{~h}$ of collection.

\section{Protein Quantitation}

The saliva was clarified by centrifugation, and the amount of protein in the clarified saliva was determined by ninhydrin analyses after wet washing [Moore and Stein, 1948] using glycine as a standard.

\section{Gtf ELISA}

We determined specific Gtf (B, C, D) present in the salivary samples using an ELISA assay by employing a kit assay obtained form Kirkegaard and Perry Laboratories, Gaithersburg, Md., USA [Voller et al., 1979; Clark and Engval, 1980]. Clarified saliva was mixed in a 1:1 ratio with the coating buffer supplied in the kit and was coated onto 96-well plates. After washing, antibodies to $\mathrm{Gtf} B, \mathrm{C}$ and D were applied. All of the buffers and reagents, which were supplied in the kit, were prepared according to the manufacturer's instructions, and the assays were performed according to the methods outlined in the manufacturer's information. Controls included wells which did not contain saliva (negative) and wells which did not contain saliva but instead contained known concentrations (1 mg of protein) of purified GtfB, GtfC or GtfD (purified by our previous methods [Venkitaraman et al., 1995; Vacca Smith et al., 1996a]). After development, the intensity of the color in the wells, which correlated to the amount of purified Gtf present, was read in an ELISA reader (Bio-Rad, Hercules, Calif., USA), and the values obtained from experimental and positive control samples were each divided by the negative control values. The results from the calculations were then termed 'Absorption Index value'. An Absorption Index value $\leq 1$ would indicate that the experimental and positive control samples were not different from the negative controls, while an Absorption Index value $>1$ would indicate that the experimental and positive control samples were different from the negative control.
Vacca Smith/Scott-Anne/Whelehan/ Berkowitz/Feng/Bowen 
Table 1. Salivary values and caries activity

\begin{tabular}{|c|c|c|c|c|c|c|}
\hline \multirow[t]{2}{*}{ Variable } & \multicolumn{2}{|c|}{ Caries-active group } & \multicolumn{2}{|c|}{ Caries-free group } & \multicolumn{2}{|c|}{$\mathrm{p}$ value } \\
\hline & mean & $\mathrm{SD}$ & mean & SD & t test & Wilcoxon $^{\text {a }}$ \\
\hline $\mathrm{MS}, \mathrm{CFU} / \mathrm{ml}\left(\times 10^{5}\right)$ & 3.24 & 3.59 & 0.46 & 1.68 & 0.002 & 0.0001 \\
\hline GtfB Absorption Index & 2.21 & 0.91 & 1.46 & 0.35 & 0.001 & 0.002 \\
\hline GtfC Absorption Index & 1.38 & 0.56 & 1.13 & 0.52 & 0.13 & 0.06 \\
\hline GtfD Absorption Index & 1.70 & 0.79 & 1.75 & 1.09 & 0.86 & 0.48 \\
\hline Gtf activity (per milliliter saliva) $^{\mathrm{a}}$ & 1.12 & 0.46 & 0.97 & 0.64 & 0.41 & 0.25 \\
\hline Gtf activity (per microgram salivary protein) ${ }^{b}$ & 1.36 & 1.84 & 1.74 & 2.05 & 0.54 & 0.51 \\
\hline Protein, $\mu \mathrm{g} / \mathrm{ml}$ & $1,306.48$ & 317.10 & $1,247.90$ & 353.90 & 0.57 & 0.40 \\
\hline
\end{tabular}

${ }^{1}$ Micromoles of glucose incorporated into glucan/milliliter of saliva.

${ }^{2}$ Micromoles of glucose incorporated into glucan/microgram of salivary protein; original value multiplied by 1,000 .

\section{Gtf Activity}

Gtf activity was determined in all salivary samples by means of direct enzyme assay [Schilling and Bowen, 1988]. A measured volume of clarified saliva from each subject was exposed to ${ }^{14} \mathrm{C}$ glucosyl-sucrose (final concentration $=100 \mathrm{mmol} / 1$ sucrose, 40 $\mu \mathrm{mol} / \mathrm{l}$ dextran 9,000 in buffered- $\mathrm{KCl}, \mathrm{pH} 6.5$ ) for $4 \mathrm{~h}$ at $37^{\circ} \mathrm{C}$, to form glucans. Gtf activity by direct enzyme assay was expressed as micromol glucans formed per milliliter saliva and also per microgram salivary protein.

\section{Microbiological Analyses}

The levels of mutans streptococci (MS) in the saliva of children from both groups were determined by plating a $20-\mu l$ portion of the uncentrifuged (diluted 1:6) saliva on selective medium (mitis salivarius agar + bacitracin) [Gold et al., 1973] and calculating the number of colony forming units (CFU) of MS per milliliter saliva.

\section{Statistical Analyses}

The subjects were divided into 2 groups, those with carious lesions and those who were lesion-free. The 2-sample t-test was used to determine the significance of differences for CFU, GtfB, $\mathrm{GtfC}$ values and Gtf activity. The differences between the 2 groups were also examined using the Willcoxon rank-sum test. The significance value was set at 0.05 . Multiple logistic regression (with model selection) with CFU, GtfB, GtfC, GtfD, Gtf Act and protein as covariates was used to study the effects of these variables on the probability of the occurrence of number of carious lesions. Data analyses were performed using SAS 9.2 (SAS Institute Inc., Cary, N.C., USA). Receiver-operating characteristic plots were used to determine the sensitivity and specificity with MedCalc version 9201 (MedCalc Software, Mariakerke, Belgium).

\section{Results}

Data on dmfs were determined on 50 children, 25 of whom were caries-free and 25 of whom had severe ECC. The mean dmfs of the children with severe ECC was
Table 2. Sensitivity and specificity of salivary data on caries activity (receiver-operating characteristic plots)

\begin{tabular}{|c|c|c|c|c|}
\hline Measure & $\begin{array}{l}\text { Sensi- } \\
\text { tivity, \% }\end{array}$ & $\begin{array}{l}\text { Speci- } \\
\text { ficity, \% }\end{array}$ & Cutoff & $\begin{array}{l}\text { Area under } \\
\text { the curve }\end{array}$ \\
\hline GtfB Absorption Index & 84 & 68 & 1.5 & 0.782 \\
\hline GtfC Absorption Index & 80 & 56 & 1.06 & 0.634 \\
\hline GtfD Absorption Index & 88 & 24 & 2.16 & 0.491 \\
\hline $\begin{array}{l}\text { Gtf activity } \\
\text { (per milliliter saliva) }\end{array}$ & 75 & 52 & 0.89 & 0.571 \\
\hline Gtf activity (per micro- & & & & \\
\hline gram salivary protein) & 79 & 56 & 1.10 & 0.570 \\
\hline $\mathrm{MS}, \mathrm{CFU} / \mathrm{ml}$ & 75 & 92 & $3.3 \times 10^{4}$ & 0.853 \\
\hline
\end{tabular}

$18.72 \pm 9.0$ SD. The ECC group consisted of 15 males and 10 females ranging in age from 38 to 70 months (mean age $=55$ months) and comprised 10 African-Americans, 11 Caucasians, 2 Asians, 1 Hispanic and 1 mixed racial. The caries-free group subjects consisted of 15 males and 10 females ranging in age from 42 to 70 months (mean age $=48$ months) and comprised 4 African-Americans, 19 Caucasians, 1 Asian and 1 Hispanic.

Table 1 summarizes the results comparing values in saliva from children who were caries-active compared with those who were caries-free. The Absorption Index value for GtfB and the MS concentration were significantly different between the 2 groups. No other values showed a significant difference.

The Gtf Absorption Index correlated significantly with dmfs ( $\mathrm{p}$ value $=0.006$ ), with an odds ratio $(\mathrm{OR})$ of 14.1 (95\% CI = 2.1-94.9). Neither GtfC nor GtfD values, as measured by ELISA, correlated with dmfs. The sensi- 
tivity and specificity of GtfB as an indicator of caries activity, determined using receiver-operating characteristic plots, were 84 and $68 \%$, respectively (table 2 ).

Gtf activity as measured by direct enzyme assay failed to show any significant correlation with caries experience (table 1), whether expressed in terms of milliliters saliva or of micrograms protein.

A strong correlation was observed between the number of mutans and caries experience (table 1). The logistic regression of dmfs on CFU showed significant effect $(\mathrm{p}=$ $0.01 ; \mathrm{OR}=1.04,95 \% \mathrm{CI}=1.01-1.08$ ). The sensitivity and specificity of MS populations in detecting caries activity are shown in table 2. A correlation between Gtf values in saliva and populations of MS was not detected.

A correlation was not observed between protein concentration of the saliva and caries experience.

\section{Discussion}

Our study revealed a strong correlation between the level of GtfB, as determined by ELISA using monoclonal antibodies, with the number of clinical lesions of our pediatric subjects. The ability to measure the level of a proven virulence factor and correlate it with clinical caries activity represents a step forward toward using the assay to aid in diagnosis of caries before overt lesions are present.

The failure to find a correlation between total Gtf activity and $\mathrm{dmfs}$ scores was surprising. It is possible that a significant amount of activity was removed when the saliva was clarified, through adsorption of enzymes to surfaces of bacteria [Vacca-Smith et al., 1996b]. The activity assay measures both soluble and insoluble glucan formation [Schilling and Bowen, 1992], whereas the ELISA as used here assesses individual enzymes [Yamashita et al., 1993]. Further, it is possible that the assay measures Gtf activity from noncariogenic organisms and clearly does not distinguish different types of Gtf activity.

Our data confirmed previously reported correlations between salivary MS populations and $\mathrm{dmfs}$ [Alaluusua and Renkonen, 1983; Köhler et al., 1988; Berkowitz, 1996; Mattos-Graner et al., 2000]. The correlation between salivary $\mathrm{GtfB}$ and $\mathrm{dmfs}$ appears to be stronger, based on OR, than that between MS and dmfs. In an attempt to determine whether multiple salivary MS counts could provide better predictive power than a single assessment, Petti and Hausen [2000] examined 304 initially caries-free 6year-olds. The predictive power of a single test had a sensitivity of $29.1 \%$ and a specificity of $95.4 \%$. Using multiple MS tests and comparing $0-1$ positive tests with $2-3$ posi- tive tests, the sensitivity increased to $31.8 \%$ and the specificity to $97.6 \%$. Several authors [Grindefjord et al., 1995; van Palenstein et al., 2001; Holbrook et al., 1993] have used combinations of predictors including salivary MS to identify children at high risk to develop caries. Salivary MS counts contributed very little to identifying the atrisk groups. Using the Strip mutans chair side method to assess MS, the predictive ability varied in sensitivity $65 \%$ and specificity $86 \%$ in a low fluoride group to $40 \%$ (sensitivity) to $91 \%$ (specificity) in an optimum fluoride group. Our data are not strictly comparable because we carried out a cross-sectional study in young populations with contrasting levels of caries activity. Although the laboratory assessments were done blindly, cross-sectional studies have limitations.

We believe that using GtfB as a potential marker for caries activity has considerable advantages over cultural methods and other approaches such as PCR. GtfB is a proven virulence property of $S$. mutans. Therefore, the test proposed here includes an agent directly involved in the pathogenesis of the disease. The test as envisaged could be used chair side and provide results within minutes. It is difficult to imagine primer and PCR mutans counts being used chair side, however carried out, as they require days to develop and need some laboratory equipment. In addition, as Bowden [1997] pointed out, cultural methods do not differentiate among clonal types which may or may not be associated with virulence. This observation may also in part account for the relatively poor performance of MS counts as predictors of caries development. It may also explain why a correlation between MS counts and Gtf was not observed in this study (data not shown).

Data from a diverse range of different tests show a correlation with dmfs or DMFT in large populations, especially adults. For example, some tests determine the salivary and plaque populations of cariogenic micro-organisms such as lactobacilli and streptococci [Rogosa et al., 1951; Duchin and van Houte, 1978; Köhler and Bratthall, 1979; Beighton, 1991; Eisenberg et al., 1991; Leverett et al., 1993a, b]. Other methods have been used to identify aciduric and acidogenic organisms in saliva or in plaque, such as the Swab test and the Snyder test [Snyder, 1951; Grainger et al., 1965]. These tests are based on colorimetric measure of $\mathrm{pH}$ changes in culture media inoculated with either saliva or plaque samples. They appear to have little predictive value as applied to individuals and generally cannot be conducted at chair side.

An ideal test for caries activity is one that could determine caries activity prior to the onset of lesions. The best 
predictor of future caries experience thus far involves assessing the presence of carious lesions already present on tooth surfaces [Grainger and Nikiforuk, 1960; Stamm et al., 1993; Hausen 1997; Powell 1998; Messer, 2000], which from a clinical perspective is rather late.

Our data represent an essential first step in developing a simple and reliable caries activity and predictive test. The strong correlation between lesions and GtfB is certainly encouraging. A problem with our study and indeed all cross-sectional studies is that one has to assume that all clinical caries-free subjects are caries-inactive at the time of sampling. We have a strong suspicion that this was not necessarily so because 2 children who were considered caries-free but displayed high Gtf levels were found to have carious lesions 3-6 months after initial examination. Clearly, this difficulty could be obviated by a longitudinal study in similar populations. The sum of sensitivity and specificity should reach a value of 140 at least for high-risk prediction [Stamm et al., 1993]. Our data show that the GtfB and CFU/milliliter MS met this value (152 vs. 167). Clearly, the true clinical value of our approach remains to be determined until the completion of a longitudinal study.

ECC constitutes a major public health problem and affects those who are least able to bear either the financial or health burden. Children in underserved areas visit a physician more readily than a dentist. If a simple test is developed, such as described here, it could be used by the physician to screen the children for caries risk during 'well child' visits and then make appropriate referrals of those identified as high risk to a dentist for the institution of preventive procedure, perhaps reducing the incidence of dental caries, obviating the need for extensive restorative care.

\section{Acknowledgments}

This study was supported by USPHS R21DE015564. We are grateful to Dr. John Daiss for discussion of ROC analysis.

\section{References}

-Alaluusua S, Renkonen OV: Streptococcus mutans establishment and dental caries in children from 2 to 4 years old. Scand J Dent Res 1983;91:453-457.

Beighton D: The value of salivary bacterial counts in the prediction of caries activity; in Johnson NW (ed): Risk Markers for Oral Diseases. Dental Caries. Cambridge, Cambridge University Press, 1991, pp 313-326.

Berkowitz R: Etiology of nursing caries: a microbiologic perspective. J Public Health Dent 1996;56:51-54

Bowden GH: Does assessment of microbial composition of plaque/saliva allow for diagnosis of disease activity of individuals? Community Dent Oral Epidemiol 1997;25:76-81.

Clark BR, Engval E: Enzyme Immunoassay. Boca Raton, CRC Press Inc, 1980

Duchin S, van Houte J: Relationship of Streptococcus mutans and lactobacilli to incipient smooth surface dental caries in man. Arch Oral Biol 1978:23:779.

- Eisenberg AD, Mundorff SA, Featherstone JD, Leverett DH, Adair SM, Billings RJ, Proskin HM: Associations of microbiological factors and plaque index with caries prevalence and water fluoridation status. Oral Microbiol Immunol 1991;6:139-145.

-Gold OG, Jordan HV, van Houte J: A selective medium for Streptococcus mutans. Arch Oral Biol 1973;18:1357-1364.
Grainger RM, Jarrett M, Honey SL: Swab test for dental caries activity: an epidemiological study. J Can Dent Assoc 1965:31:515.

Grainger RM, Nikiforuk G: Determination of relative caries experience. J Can Dent Assoc 1960;26:531.

Grindefjord M, Dahllof G, Nilsson B, Modeer T: Prediction of dental caries development in 1-year-old children. Caries Res 1995;29:343348.

Hamada S, Slade HD: Biology, immunology, and cariogenicity of Streptococcus mutans. Microbiol Rev 1980;44:331-384.

-Hanada N, Kuramitsu HK: Isolation and characterization of the gtfC gene, coding for synthesis of both soluble and insoluble glucans. Infect Immun 1988;56:1999-2005.

-Hanada N, Kuramitsu HK: Isolation and characterization of the Streptococcus mutans gtfD gene, coding for primer-dependent soluble glucan synthesis. Infect Immun 1989;57: 2079-2085.

- Hausen H: Caries prediction - state of the art. Community Dent Oral Epidemiol 1997;25: 87-96.

Holbrook WP, de Soet JJ, de Graaff J: Prediction of dental caries in pre-school children. Caries Res 1993;27:424-430.

Ivanyi J, Davies P: Monoclonal antibodies against human growth hormone. Mol Immunol 1980;17:287-290.

-Köhler B, Andreèn I, Jonsson B: The earlier the colonization by mutans streptococci, the higher the caries prevalence at 4 years of age. Oral Microbiol Immunol 1988;3:14-17.
Köhler B, Bratthall D: Practical method to facilitate estimation of Streptococcus mutans levels in saliva. J Clin Microbiol 1979;9:584588

Leverett DH, Featherstone JD, Proskin HM, Adair SM, Eisenberg AD, Mundorff-Shrestha SA, Shields CP, Shaffer CL, Billings RJ: Caries risk assessment by a cross-sectional discrimination model. J Dent Res 1993a;72: 529-537.

Leverett DH, Proskin HM, Featherstone JD, Adair SM, Eisenberg AD, Mundorff-Shrestha SA, Shields CP, Shaffer CL, Billings RJ: Caries risk assessment in a longitudinal discrimination study. J Dent Res 1993b;72:538543.

Loesche WJ: Role of Streptococcus mutans in human dental decay. Microbiol Rev 1986;50: 353-380.

-Mattos-Graner RO, Smith DJ, King WF, Mayer MPA: Water-insoluble glucan synthesis by mutans streptococcal strains correlates with caries incidence in 12- to 30-month-old children. J Dent Res 2000;79:1371-1377.

- Messer LB: Assessing caries risk in children. Aust Dent J 2000;45:6-10.

Milnes AR: Description and epidemiology of nursing caries. J Public Health Dent 1996;56: 38-50.

Moore S, Stein WH: Photometric ninhydrin method for use in the chromatography of amino acids. Biol Chem 1948;176:367-368. 
- Petti S, Hausen HW: Caries prediction by multiple salivary mutans streptococcal counts in caries-free children with different levels of fluoride exposure, oral hygiene and sucrose intake. Caries Res 2000;34:380-387.

Powell LV: Caries prediction: a review of the literature. Community Dent Oral Epidemiol 1998;26:361-371.

Radike AW: Criteria for diagnosing dental caries; in Proceedings of the Conference on Clinical Testing of Cariostatic Agents, 1968. Chicago, American Dental Association, 1972, pp 87-88.

Rogosa M, Mitchell JA, Wiseman RE: Selective medium for the isolation and enumeration of oral lactobacilli. J Dent Res 1951;30:682684.

Schilling KM, Blitzer MH, Bowen WH: Adherence of Streptococcus mutans to glucans formed in situ in salivary pellicle. J Dent Res 1989;68(spec iss):678-680

Schilling KM, Bowen WH: The activity of glucosyltransferases adsorbed onto saliva-coated hydroxyapatite. J Dent Res 1988;67:2-8.

$\checkmark$ Schilling KM, Bowen WH: Glucan synthesized in situ in experimental pellicle functions as specific binding sites for Streptococcus mutans. Infect Immun 1992;60:284-295.
Snyder ML: Laboratory methods in the clinical evaluation of caries activity. J Am Dent Assoc $1951 ; 41: 400$

Stamm JW, Disney JA, Beck JD, Weintraub JA, Stewart PW: The University of North Carolina caries risk assessment study: final results and some alternative modeling approaches; in Bowen WH, Tabak LA (eds) Cariology for the Nineties. Rochester, University of Rochester Press, 1993, pp 209234.

Tinanoff N: Introduction to the early childhood caries conference: initial description and current understanding. Community Dent Oral Epidemiol 1998;23(suppl 1):5-7.

Vacca-Smith AM, Bowen WH: In situ studies of pellicle formation on hydroxyapatite discs. Arch Oral Biol 2000;45:277-291.

Vacca-Smith AM, Venkitaraman AR, Quivey RG, Bowen WH: Interactions of streptococcal glucosyltransferases with alpha-amylase and starch on the surface of saliva-coated hydroxyapatite. Arch Oral Biol 1996a;30:291298.

Vacca-Smith AM, Venkitaraman AR, Schilling KM, Bowen WH: Characterization of glucosyltransferase of human saliva adsorbed onto hydroxyapatite surfaces. Caries Res 1996b;30:354-360.
-Van Palenstein Helderman WH, Mikx FH, Van't Hof MA, Truin G, Kalsbeek H: The value of salivary bacterial counts as a supplement to past caries experience as caries predictor in children. Eur J Oral Sci 2001;109:312-315.

-Venkitaraman AR, Vacca-Smith AM, Kopec LK, Bowen WH: Characterization of glucosyltransferase $B$, gtfC, and gtfD in solution and on the surface of hydroxyapatite. J Dent Res 1995;74:1695-1701.

Voller A, Bidwell DE, Bartlett A: The EnzymeLinked Immunosorbent Assay (ELISA). A Guide with Abstracts of Microplate Applications. Alexandria, Dynatech Laboratories Inc, 1979.

$\checkmark$ Wood JM, Critchley P: The extracellular polysaccharide produced from sucrose by cariogenic streptococcus. Arch Oral Biol 1966;11: 1039-1042.

Wunder D, Bowen WH: Effects of antibodies to glucosyltransferase on soluble and insolubilized enzymes. Oral Dis 2000;6:289-296.

Yamashita Y, Bowen WH, Burne RA, Kuramitsu HK: Role of the Streptococcus mutans gtf genes in caries induction on the specificpathogen-free rat model. Infect Immun 1993;61:3811-3817. 